\title{
SIMULATION OF A BASE STOCK INVENTORY MANAGEMENT SYSTEM INTEGRATED WITH TRANSPORTATION STRATEGIES OF A LOGISTIC NETWORK
}

\author{
EunSu Lee \\ Transportation and Logistics Program \\ North Dakota State University \\ $161612^{\text {th }}$ Avenue North \\ Fargo, ND 58102 USA
}

\author{
Kambiz Farahmand \\ Dept. of Industrial and Manufacturing Engineering \\ North Dakota State University \\ 202N Civil and Industrial Engineering Building \\ Fargo, ND 58102 USA
}

\begin{abstract}
A logistics network management system controlling the entire supply chain was designed to reduce the total cost and to achieve an efficient system. The interactions between inventory and transportation strategies in the logistics network are presented in this paper. Demand volumes and shipping sizes were simulated as part of a new conceptual model by using a discrete event simulation to minimize the total cost in the supply chain. The experiments indicate that the Full Truckload scenario leads to cost-efficiency and the larger demand size results in smaller cost per unit based on economies of scale. Considering the interaction effects, the demand size has a greater impact on the cost reduction than the shipping size.
\end{abstract}

\section{INTRODUCTION}

Companies experience business expansion or shrinkage due to market changes. Efficient coordination of logistics networks is required to lead today's competitive market. Companies consider redesigning the logistics network model, including manufacturers, distribution centers, and warehouses to minimize the total cost and to maximize the customer service. Long-term planning for the network design is considered when investing in resources or contracts with third-party logistics companies.

The total cost is determined based on location, transportation, and inventory costs. To optimize the logistics network model, the factors affecting cost are considered. Pujawan (2004) studied the effective lot sizing rules by comparing the variance of order interval and quantity. He focused on the order variability under different order lot sizes without considering shipping cost and location capacity in a single level system from suppliers to end customers. The majority of the studies in the literature use mathematical optimization techniques or Monte Carlo simulation. To consider optimizing all the systems in a company, the discrete simulation technique is used to deal with complexity of factors and strategies (Ruiz-Torres 1997). Due to many assumptions and numerous responses to potential factors of logistics network simulation, the abstracted process in lieu of the detailed process is considered as in the earlier research by Suwanruji (2004) and Jain (1999) as well as a metamodel (Song et al. 2008). Kleijnen (2005) indicated simulation as a tool of methodological concerns: verification, sensitivity or "what-if" analysis, optimization, and robustness and uncertainty analysis for strategic levels.

Anily and Federgruen (1993) researched fixed renting truck cost and constant replenishment interval inventory policy. They used deterministic demand and assumed the demand is identically uniform for all regions through two echelons. Qu et al. (1999) modeled a logistics network with stop over, travel, and shipping cost. Jayaraman (1998) studied a logistics network with the space of locations limited by the dimension of products. 


\section{Lee and Farahmand}

In the supply chain system, most of the products flow on pallets or in bulk from higher echelons. A pallet is a typical unit in a supply chain for the inbound and outbound process. Vroblefski et al. (2000) researched lot-sizing model as Truckload (TL) and Less-Than-Truckload (LTL) under a differential transportation cost structure. Chu (2005) studied mode selection between TL and LTL carriers for cost savings for a given company. Different products have different dimensions and lot-sizes. However, the study excluded inventory rules. To optimize the entire transportation and logistics system of a company, a discrete simulation technique is required to overcome complexity and variability of factors and strategies (RuizTorress 1997, Song et al. 2008). Due to many assumptions and numerous responses to potential factors of logistics network simulation, abstracted process in lieu of detailed process is considered (Pujawan 2004, Jain 1999).

In this study, a discrete-event simulation is used to experiment with the continuous base stock inventory policy integrated shipping strategies by the various demand sizes. The simulation model collected cost data for analysis. The first objective of this study was to verify the key role of the interaction between inventory control and transportation strategy in different demand sizes for the multi-echelon logistics network model. This paper focuses on the interaction of demand sizes and trucking lot-sizes for the complex logistics network design.

\section{SYSTEM DESCRIPTION}

To manage the customer's service, there are three types of nodes in the logistics network considered in our model: factories, Regional Distribution Centers (RDC), and warehouses as shown in Figure 1. It is assumed that factories are uncapacitated, and RDCs and warehouses are capacitated.

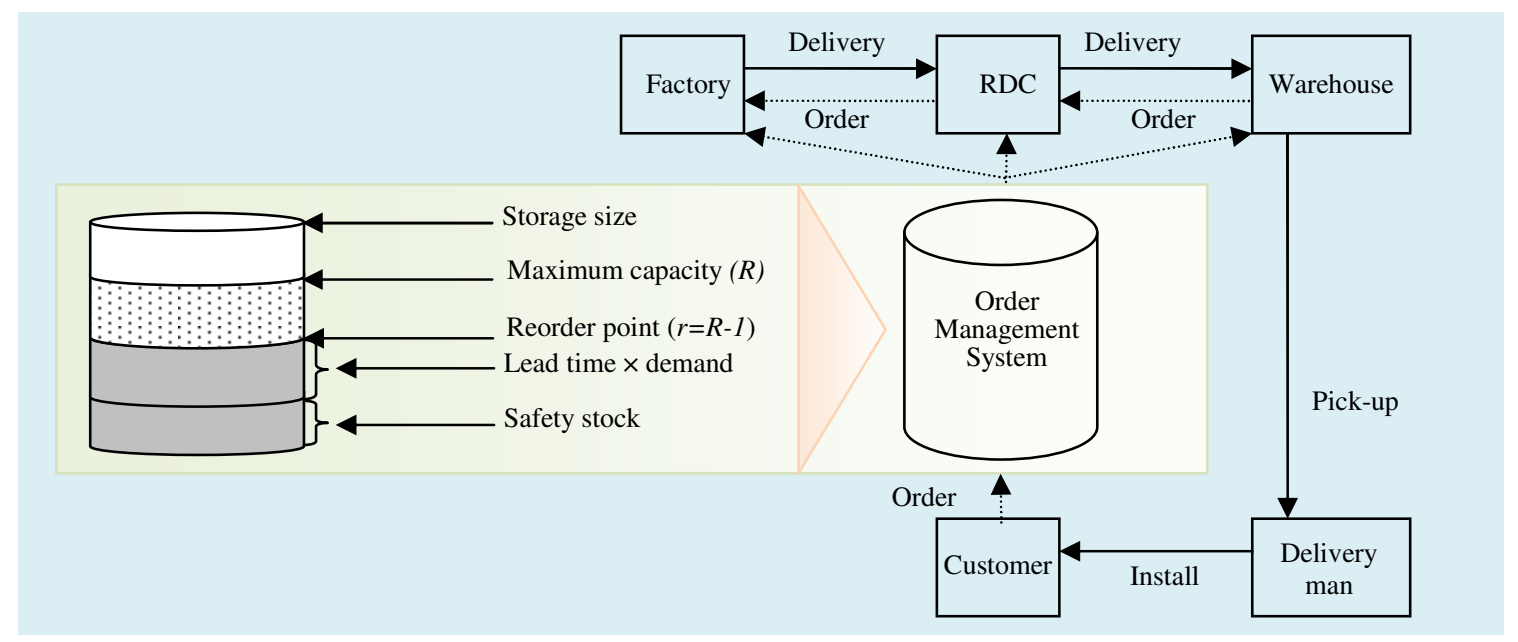

Figure 1: Multi location model with inventory system

Three factories manufacture different products respectively and serve three distribution centers. Factories operate warehouses to store the manufactured products and returned products. The three RDCs have two main functions. The first function is to supply products to warehouses as a main distribution center. The second is to maintain safety stocks to satisfy rush orders as they arrive. RDCs keep all products over the safety stock level for the unexpected sales. Forty five warehouses are assigned to RDCs, and new warehouses will be allocated to the closest RDC to minimize the transportation cost in order to shorten travel distances while considering the capacity of that RDC. All customer orders are stored in the Order Management System (OMS). To finalize the original orders, it will take three days in order to check the customer's credit. In such a system, customers are required to order products at least three days ahead of the delivery schedule. Each facility places an order to a higher echelon to maintain the customer's original demand from OMS including rush orders from the Customer Service Center in the Sales Department 


\section{Lee and Farahmand}

or the customers themselves directly. To realize the benefits of the RDCs in a logistics network, the company considers both routes and the size of trucks. If RDCs do not have enough capacity for sizable carriers, the total cost cannot be reduced to achieve economies of scale. The factories and the RDCs have spacious docking systems and parking lots for trucks of a gross weight of 15 tons. The warehouses are located in suburban areas because of the cost of land, taxes, and building restrictions. For this reason, a gross weight of 2.5 to 5 tons is the ideal truck size for the narrow feeding road under the constraints. The shipping is outsourced to the freight companies and factories, and the freight companies are contracted on a daily basis, so even if the truck is idle, the company pays the shipping cost.

\section{EXPERIMENT DESIGN}

\subsection{Parameters}

The following formulations in this section used the following nomenclature:

$F Q_{f}=$ Number of factories

$F Q_{r}=$ Number of RDCs

$F Q_{w}=$ Number of warehouse

$F F_{f t}=$ Fixed facility cost of a factory during the period $t$

$F F_{r t}=$ Fixed facility cost of a RDC during the period $t$

$F F_{w t}=$ Fixed facility cost of a warehouse during the period $t$

$F V_{f t}=$ Variable facility cost of a factory during the period $t$

$F V_{r t}=$ Variable facility cost of a RDC during the period $t$

$F V_{w t}=$ Variable facility cost of a warehouse during the period $t$

$Q_{\text {frpt }}=$ Number of units of product $p$ shipped from factory to RDC during the period $t$

$Q_{r w p t}=$ Number of units of product $p$ shipped from RDC to warehouse during the period $t$

$\operatorname{Tr} V^{z}=$ Variable transportation cost per hour

$\operatorname{Tr} F_{t}{ }^{z}=$ Fixed Transportation Cost of a type of truck $Z$ during the period $t$

$T Q^{z}=$ Number of trucks of the size of $z$

$D_{w p}=$ Number of product $p$ in demand at warehouse per unit

$D_{r p}=$ Number of product $p$ in demand at RDC per pallet

$R O P_{w p}=$ Reorder point of product $p$ at warehouse

$R O P_{r p}=$ Reorder point of product $p$ at RDC

$I_{w p}=$ Current inventory of product $p$ at warehouse

$I_{r p}=$ Current inventory of product $p$ at RDC

$A I_{r p t}=$ Average inventory of product $p$ at RDC during the period $t$

$A I_{w p t}=$ Average inventory of product $p$ at warehouse during the period $t$

$L_{p}=$ Number of product $p$ on a pallet

$\operatorname{Pr}_{p}=$ Market price of product $p$

\subsection{Objective}

The objective of this simulation is to minimize the total cost of the overall systems in the supply chain from factories to warehouses. Total logistics cost is determined by adding the transportation cost, inventory cost, facility cost, and stockout cost (1).

$$
T C=\text { Transportation Cost }(\operatorname{Tr} C)+\text { Inventory Cost }(I C)+\text { Facility Cost }(F C)+\text { Stock out Cost }(S C)
$$

Demand size and shipping size are experimented with base stock inventory policy to achieve the research objective. Different configurations of trucks are considered based on different levels of echelon. 


\section{Lee and Farahmand}

$\operatorname{Tr} C$ (2) consists of variable transportation costs and fixed transportation costs between the manufacturers, regional distribution centers, and warehouses. Fixed transportation cost is calculated based on the different types of trucks, which are used between the various facilities. These different size trucks assign different fixed cost to the cost model. Variable transportation cost is determined by the hours of operation. The hours are calculated by dividing the distance by the speed of truck considering fully or partially loaded truck and empty back-haul truck without regarding capacity or size of the trucks.

$$
\operatorname{Tr} C=\operatorname{Tr} V^{z}\left(h_{f r t}^{z}+h_{r w t}^{z}\right)+T r F_{t}^{z} \cdot T Q^{z}
$$

$I C$ consists of Ordering Cost $(O C)$ for each order and Carrying Cost $(C C)$ to hold the inventory during a given period. Order cost is based on one-for-one inventory policy (141) (3). Order lot sizes are managed in both RDCs and warehouses. It means that the pallets could be moved from RDCs to factories or from warehouses to RDCs as part of fulfilling orders. Order cost of one-for-one policy is the frequency of orders at each facility times the cost per order. The number of units to be ordered in RDC should be bigger than the number of units on a pallet for each product. In the RDCs, the total number of units is determined by subtracting the reorder point from current inventory. The total units are then divided by the number of products on a pallet to determine the total number of pallets. In the warehouse, orders are generated when the reorder point is higher than the current inventory level. Carrying cost (4) is then calculated by multiplying the average number of units in the facility during a given period times some percentage cost of a product. The interest rate is assumed 12\% APR when calculating the carrying cost. The equations presented by Lee and Farahmand (2008) are as follows:

$$
\begin{aligned}
& O C=\sum_{p=1}^{P}\left\{\operatorname{Max}\left\{0, \operatorname{Trunc}\left(\frac{D_{w p}}{L_{p}}\right)\right\}+D_{r p}\right\} \cdot C O \\
& C C=\sum_{t=1}^{T} \sum_{p=1}^{P}\left\{\left(A I_{r p t} L_{p} \operatorname{Pr}_{p}\right)+\left(A I_{w p t} \operatorname{Pr}_{p}\right)\right\} \cdot(12 \%)
\end{aligned}
$$

$F C$ is the combination of variable facility cost $(F V)$ and fixed facility cost $(F F)$. Total fixed facility cost shown in Equation (5) is a product of the total number of facilities and unit cost for each facility based on the type of locations during a given period. Facility variable cost shown in (6) consists of two parts in a facility based on material handling cost and other costs. Material handling cost is based on cost of operating forklifts and labor cost involved.

$$
\begin{aligned}
& F F=\sum_{t=1}^{T} F F_{f t} \cdot F Q_{f}+F F_{r t} \cdot F Q_{r}+F F_{w t} \cdot F Q_{w} \\
& F V=\sum_{t=1}^{T} \sum_{p=1}^{P}\left\{F V_{f} Q_{f r p t}+F V_{r}\left(Q_{f r p t}+Q_{r w p t}\right)+F V_{w} 2\left(Q_{r w p t} L_{p}\right)\right\}
\end{aligned}
$$

Stockout cost in Equation (7) is calculated based on the current inventory level that cannot reach the demand level during a given period. The loss is assumed at $10 \%$ of the market value.

$$
S C=\sum_{p=1}^{P}\left\{\operatorname{Max}\left\{0,\left(D_{w p t}-I_{w p t}\right)\right\} \cdot \operatorname{Pr}_{p}\right\} \cdot(10 \%)
$$




\section{Lee and Farahmand}

\subsection{Inventory}

It is assumed that inventory is based on F.O.B. (Free On Board) delivery, which means that the seller or supplier takes the responsibility of transportation charges and delivery. For this reason, the supplier's inventory will be updated at the moment the inbound product enters into the customer's facilities. The order is then decentralized as a pull system, which means that each facility places an order for replenishment independently as shown in Figure 2.

\subsubsection{Demand and Order}

The transportation and material handling at the factory and RDC operate 24 hours a day. The orders are closed at 6:00 p.m. every day by the information system. The model is denoted as $(r, R)$ with $R=r+1$, where $R$ is maximum capacity (upper bound) and $r$ is the reorder point as shown in Figure 2. Only one unit is ordered when the inventory level reaches the reorder point $(r)$. For the simulation purposes, the $R$ is set as the product of maximum utilization and the storage size of a location. Each warehouse is assumed to store 500 products without consideration for the item's physical dimensions. Maximum capacity $(R)$ excludes the dock, the parking lot, dead space, office space, etc.

RDC has adequate parking lots, docking systems, and roads for trucks and trailers. RDC is located in suburban areas, and the warehouse is located in urban areas for quick delivery and service. The warehouse has a small parking lot and narrow feeding road that makes it difficult for big trailers or trucks to enter. The capacity constraint is to satisfy the minimum demand. In this study, the maximum capacity is set at the average daily demand for one day. The upper bound is calculated by max \{space $\times$ height $\times$ efficiency / pallet dimension, Arbitrary number\} at each location $i$. Melachrinoudisa et al. (2005) used the warehouse-utilization ratio and the number of pallets. The maximum utilization is set equal to the capacity of a location and then is converted into the number of pallets.

In the proposed simulation model, external demand occurs at the lowest echelon which is the warehouses in a normal distribution model. The total sale of products, however, is continuously increasing. The scenarios of demand sizes are assumed in units of 3,5, and 7 millions. The demand size is divided by the total business days (365) in a year for the daily arrival rate. Two years of outbound data are tested in the STAT:FIT utility of Promodel®. From the results, normal distribution is chosen as the distribution of choice to simulate the outbound data. The goodness of the fit test is conducted by Maximum Likelihood Estimates with an accuracy of the FIT of 0.0003 and a level of significance of 0.05 . From the data, each day's demand of a product is set by $A=N(D Y / N B, D Y / N B * R D)$, where $A=$ Daily arrival rate; $N=$ Normal distribution (mean, standard deviation); DY = Expected demand per year; NB = Business days per year; $\mathrm{RD}=$ Rate of standard deviation of the mean.

Initial inventory is set up for a new business. It is set as a default value before the entities arrive in the simulation system. Inventory cost is classified into three categories: stockout cost, holding cost, and ordering cost. Stockout cost is assumed as $10 \%$ of the product margin. It is assumed holding cost consisted of storage managing cost as $7 \%$ of the average inventory, storage risk as $5 \%$ of the average inventory, and interest rate of $12 \%$ per year. Ordering cost is calculated by $\$ 1.00$ per item.

\subsection{Location}

Each warehouse is assigned to a RDC. A RDC distributes products to the assigned warehouses. Factory and RDC have the many-to-many (m:m) relationship, and RDC and warehouses have the one-to-many $(1: m)$ relationship to each other in terms of supplying and service.

The average space of factories and RDCs is 4,000 square meters, and the efficiency of the locations is around $80 \%$ excluding dead space. They can accommodate 1,000 pallets. The average space for a warehouse is $700 \mathrm{~m}^{2}$, and the efficiency of warehouses is $60 \%$. Each warehouse would store nearly 500 products without consideration of the item's various dimensions. Capacities of the location exclude dock, 


\section{Lee and Farahmand}

parking lot, dead space, office space, etc. The operation costs of locations are differentiated by the level of daily operation. The fixed cost was $\$ 7500$ at a factory and RDC and $\$ 650$ at a warehouse. The variable cost was $\$ 3$ at a factory and $\$ 5$ at a RDC per pallet, while the variable costs were $\$ 1$ per item at a warehouse.

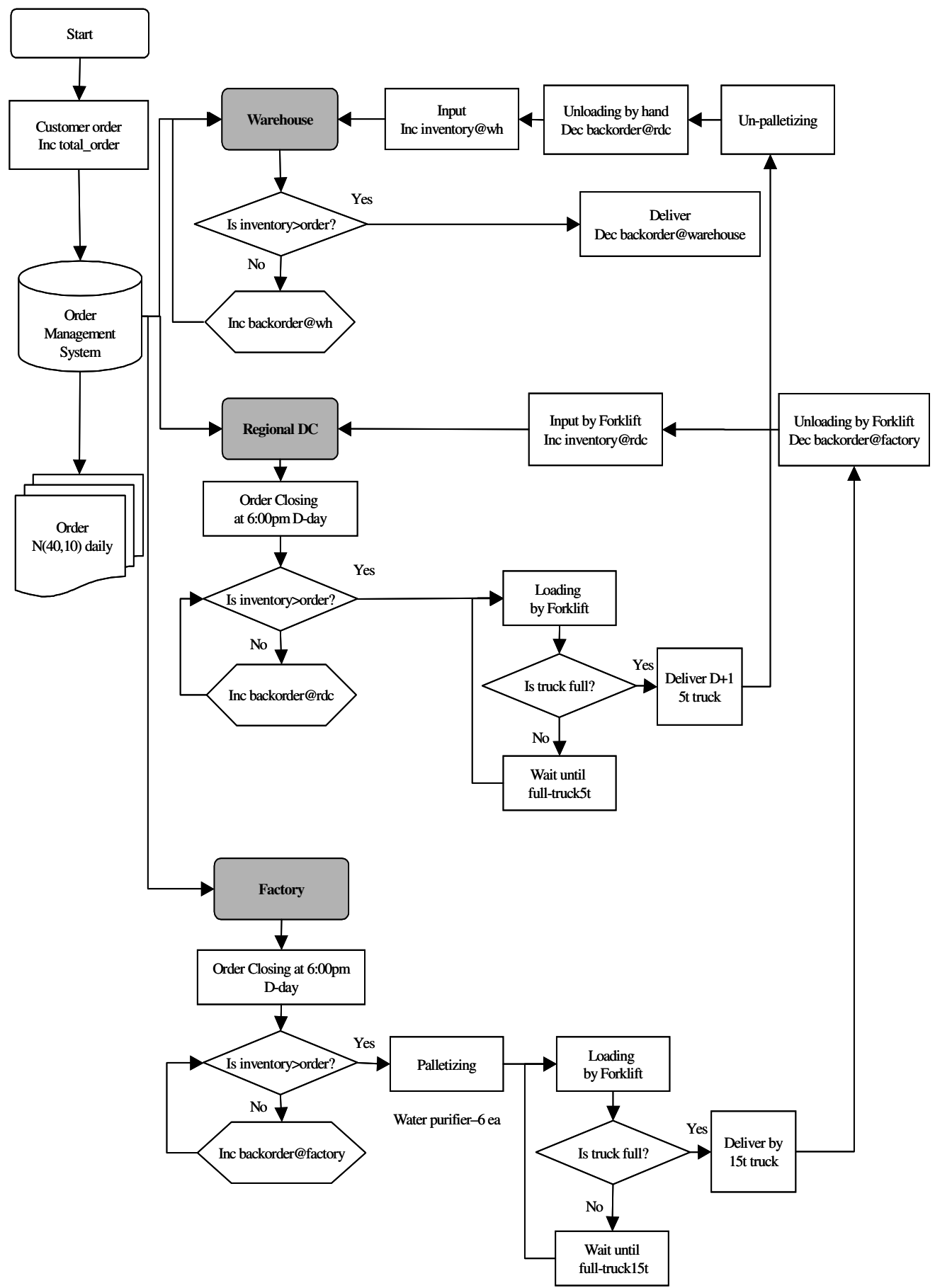

Figure 2: Flow of process 


\section{Lee and Farahmand}

\subsection{Material Handling}

Forklifts are used at factories and RDCs, which are spacious, but not at warehouses. To use a forklift, products should be palletized at a factory and orders are placed in pallets. The number of products on a pallet varies based on different dimensions of products. For example, six items of product A along with 18 items of product $\mathrm{B}$ could be loaded on a pallet. The pallets move from a factory to a RDC, and from a RDC to a warehouse. The pallets are kept in these locations until delivered. Those pallets are ungrouped at a warehouse for delivery to customers. The simulation setting for the forklift is summarized in Table 1 .

Table 1: Forklift operation data collected at factories and RDCs

\begin{tabular}{ll}
\hline Activities & Quantification \\
\hline Pickup time & 1 minute \\
Deposit time & 3 minutes \\
Travel speed in loading & 4 meters/minute \\
Travel speed not in loading & 4 meters/minute \\
Distance from shipping dock to rack & 50 meters \\
Cost $(\$)$ per hour & $\$ 30$ \\
\hline
\end{tabular}

\subsection{Transportation}

The configuration of a truck has its own capacity to load products accumulated in different units, such as weight, volume, and dimension. This was tested here in two different shipment sizes of truckload (TL) shipment and less-than-truckload (LTL) shipment. TL is set at full capacity for the experiment, and LTL is at $50 \%$ of the capacity of TL.

Weight is not an issue since the company's products are dimensional products instead. In this model, the areas for palletizing and depalletizing were considered as part of the flow of products. The products were palletized with the average dimension of the stock keeping units (SKU). Palletizing time at a factory was not considered because the activity is done after production, not at the time of receiving an order. The palletized products were moved into the loading field by a forklift. Thirty six pallets were loaded in a 15 ton truck and 10 pallets were loaded on a 5 ton truck. The fixed cost was $\$ 130$ for a 15 ton truck and $\$ 100$ for 5 ton truck. The variable cost was $\$ 30$ for a 15 ton truck and $\$ 25$ for a 5 ton truck.

Transportation delay is a major portion of lead-time since this study is considering the shipping sizes in order to ship products from origin to destination. Nonetheless, speed variability is simulated to express the lead time instead of using the predetermined lead time for shipping. The empty trucks drive $U(80,18)$ $\mathrm{Km}$ per hour; however, the loaded trucks drive $\mathrm{U}(72,12) \mathrm{Km}$ per hour following a uniform distribution assumption. The waiting time for deposit at each locations was set by $U(1800,600)$ seconds for inspection and documentation activities while unloading products.

LTL is loaded under $100 \%$ of the capacity of TL delivery. For example, when a factory receives the order for the quantity of $50 \%$ of TL, the truck transports those products to lower echelon. The lead-time might be shorter than TL. However, the cost will be increased due to the frequency. TL shipment could be designed to decrease the handling cost and variable shipping cost. It is assumed that there is no surcharge for the carriage service. The company distributes the products by the unit of pallet from a supplier to a warehouse. In this model, the zone of palletizing and depalettizing were considered as steps in the flow of the products as shown in Figure 3.

The transportation cost is calculated monthly using a fixed cost. Although, if it is over some distance of kilometers from the location specified in the contract, the company charges more money as an additional variable cost. 
Lee and Farahmand

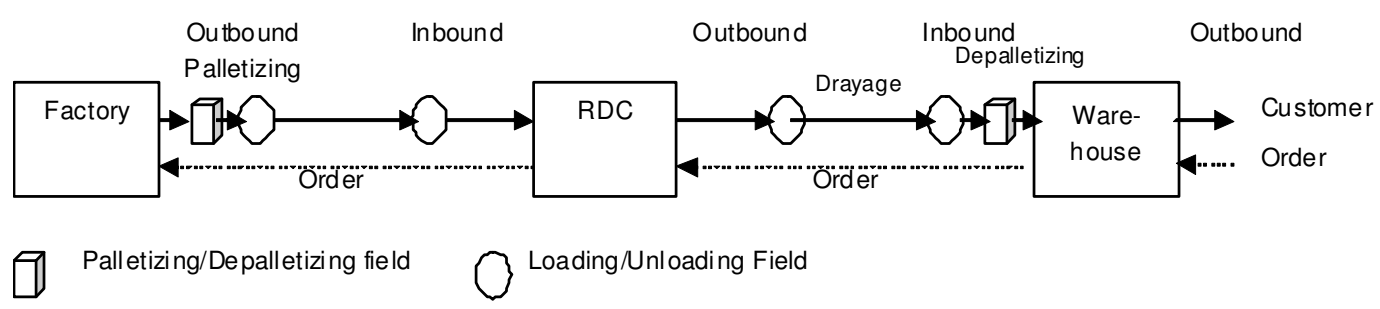

Figure 3: Transportation diagram

\subsection{Verification}

The conceptual logistics network model for this study was verified. Verification is an important process to determine if simulation is correctly working. Outputs from the simulation are categorized into four groups: the number of orders and deliveries, the number of backorders, inventory levels, and costs. Animation screens were designed to see the flow of products and the movement of resources, and the changes of inventory levels and capacity. The screens are saved, depending on the inventory policies, as scenarios into different screens. The demand and transportation policy factors are set in the "macro" menu to change simulation options easily.

The results of the simulation model will have impacts on management decisions and their outcome; therefore the results should be accurate and representative of the operation (Banks et al. 2005). A variety of validation methods were introduced by Sargent (2004) and Sargent (2009) including an animation, comparison to other models, degenerate tests, extreme condition tests, and historical data validation. Sensitivity analysis is conducted for validation of the model. Historical data validation to represent the reality can be used when the reality model is developed to improve the current system. Even though real data was not collected for our study, the historical method was used for validating the assumptions and general acceptance for the model scenarios. Furthermore, an operational graphics method was performed. Through this method, it was observed that the entities' dynamical behaviors run through the model's runtime.

\section{EXPERIMENTATION}

\subsection{Simulation}

Nine scenarios $(3 \times 3)$ for experimental analysis are run and discussed; three demand sizes and three shipping sizes. Eleven months' data are collected to analyze with one month warm-up period to reach the steady-state period in a series of replications after running all scenarios of the simulation. Farahmand and Balasubramanian (2002) set the warm-up period after running all the categories of the simulation scenarios. The maximum period to reach the steady-state period is set as a warm-up period in a series of replications. In the real world, the initial inventories are set up for new business, so the warm-up period does not have to be long in this simulation. Each scenario is run for 30 days to plot the warm-up period for the stable statistics and to reach steady-state outputs of entities for secure simulation.

To ensure the sample observations, the bias was removed or reduced in the experiment. There are two methods for independent sample observations: running multiple replications and interval batching. In this study, the running multiple replication method is used. For the simulation experiment, the replication is considered as a sample size to avoid the bias of random variability. The replications have different seed values when ProModel ${ }^{\circledR}$ generates the random number for the simulation. The technique has an advantage in that each replication should be set with a warm-up period to avoid biased results. 


\section{Lee and Farahmand}

\subsection{Experimental Results}

All data are mean values of a day-run from each scenario.

\subsubsection{Results and Discussion}

LTL is used for rush order or quick replenishment to meet a customer's delivery date. It is also used for small quantities of items. LTL results in long distance of travel overall, and it slows the replenishment due to the down-time and low utilization of trucks. Simulation is run with and without the stockout constraint. In this model, the results show that TL is more efficient than LTL as demand size increases.

Cost analysis is summarized in Fig. 4. Total cost is collected from the simulation, and unit cost is calculated to compare the transportation policies. The concern is how a company can keep the cost reasonable to maximize profit. Low cost does not mean that the company would have high profit per unit with that scenario. Trucking cost decreases as the shipping size increases and as the demand size decreases. The interaction effects between the shipping size and the demand size are not significant for the trucking cost. The material handling cost decreases as the shipping size increases and as demand decreases. The material handling cost is distorted when the shipping size is small and demand is up. The ratio of decreasing of the material cost is affected much more by demand size than the shipping size. The facility cost decreases by increasing shipping size and increasing demand size due to economies of scale. The holding shows the same pattern as the facility cost's. In addition, the ratio of cost decrease is high at the demand size. The interaction between the large demand size and the large shipping size shows the lowest unit cost level.

The simulation model was run for one year with a one month of warm-up period. The warm-up period is not counted in the results; however, the output data is collected for 11 months. The output is measured by the unit cost of each item of trucking, material handling, ordering, holding, and facility costs as shown in Table 2. The number of orders is used as a numerator to get the unit costs.

Prior analysis is based on the point estimators of the replication parameters $\mu$, which vary on different sets of observations from cost behavior. This paper construct interval estimates using $95 \%$ confident interval to inform the distance of the point estimates from multiple observations. The confident level was computed by adding the half-width to the average value of the samples, $\bar{x}$. The unknown true mean lies within the interval between the lower limit and upper limit. Desirable interval would be narrow with high confidence over 90\% (Harrell et al. 2003).

Table 2: $95 \%$ confidence interval for all scenarios.

\begin{tabular}{|c|c|c|c|c|c|c|c|c|c|}
\hline \multirow{2}{*}{$\begin{array}{l}\text { Demand Size } \\
\text { Shipment Size }\end{array}$} & \multicolumn{3}{|c|}{3 million } & \multicolumn{3}{|c|}{5 million } & \multicolumn{3}{|c|}{7 million } \\
\hline & $50 \%$ & $75 \%$ & $100 \%$ & $50 \%$ & $\mathbf{7 5 \%}$ & $100 \%$ & $50 \%$ & $\mathbf{7 5 \%}$ & $100 \%$ \\
\hline Upper Limit & 51.2 & 44.1 & 39.2 & 38.3 & 31.6 & 27.2 & 32.9 & 26.2 & 21.8 \\
\hline Lower Limit & 51.0 & 43.9 & 38.9 & 38.3 & 31.5 & 27.0 & 32.7 & 26.1 & 21.8 \\
\hline
\end{tabular}

The scenario with LTL shipment (50\% of the trucking capacity) in 3milion demand indicates the worst case, while the scenario with TL shipment (100\% trucking capacity) in 7 million demand and indicates the best scenario with regard to the unit cost. Little difference is found between the scenarios of TL shipment in 3 million demand and of LTL shipment in 5 million demand. In our study, high demand generates relatively lower unit cost than smaller demand scenarios. The TL shipment scenarios, regardless of demand sizes, show the lower unit costs than the LTL shipment scenarios. It is obvious to say that the LTL shipments do not suit to the high demand sizes by causing inefficiency in terms of the unit cost. 

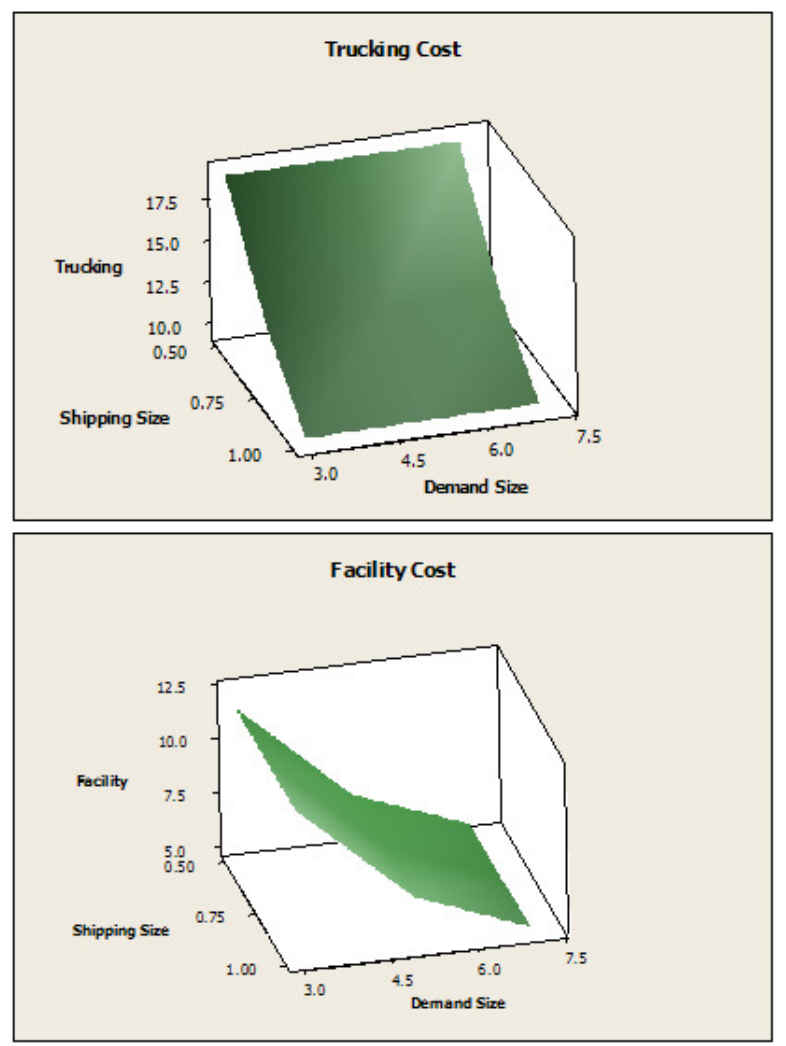
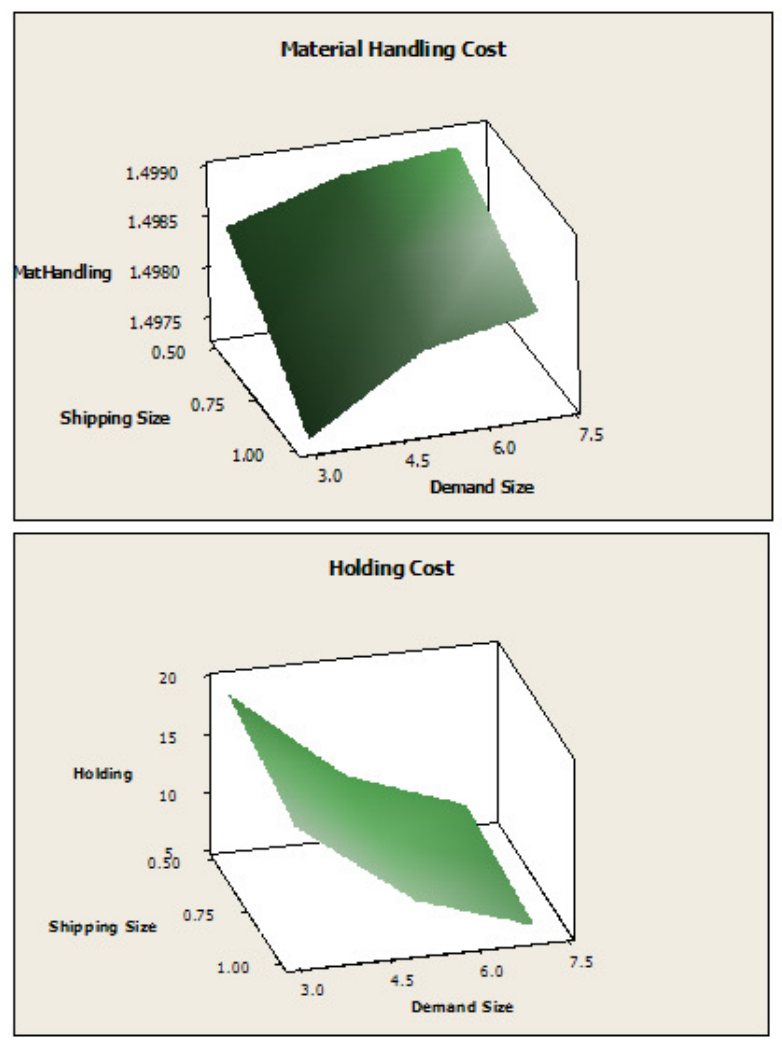

Figure 4: Surface graph for the cost items of each scenario

\subsubsection{Implications}

It is essential to understand the balancing of inbound and outbound rate and flow speed in a logistic inventory process. The implications explain the behavior of logistics cost. Inbound rate is a replenishment rate and outbound rate is represented by demand size in this study. The demand size, explained as outbound rate, is categorized into three echelons. When the replenishment rate is high and demand size is small, holding cost, handling cost, and shipping cost are high. TL shows high replenishment rate in this case and LTL with a big fleet is a source of fast replenishment rate. In reverse, when replenishment rate is low and demand size is high, stockout cost is incurred. LTL without increasing fleet size shows slow replenishment rate. When inbound and outbound rate is balanced, the cost is affected by the average rate the products are moved from origin to destination.

For fast moving products with a high demand, handling cost and shipping cost is high. One-for-one policy incurs fast rate of flow, and LTL with increasing capacity would incur high flow rate. When the flow rate is slow, stockout cost is high since the fast flow rate cripples the balance between inbound and outbound rate.

\section{CONCLUSIONS AND FUTURE WORK}

This study looks at the trade-off between inventory cost, shipping cost, and stockout cost for a multi echelon inventory management system. The total logistics cost in the system is controlled by replenishment rate and flow rates from the origins to destinations. High inventory cost is caused by fast replenishment rate and frequent orders. High shipping cost is caused by the fast flow rates in a process and total traveling time or total traveling distance. Shipping function is an important role which provides balance be- 


\section{Lee and Farahmand}

tween inbound and outbound processes. Stockout cost has occurred by slow replenishment rate in the case of high demands and slow flow rates between suppliers and customers. Shipping size also has an impact on the level of service and the total cost along with effective order variability. In the three demands scenarios, TL shows better unit profit as well as cost per unit. As the demand size is increasing, the unit cost difference is decreasing. The simulation results are fueled by the profit driven strategies, since TL has a fast replenishment rate and a fast outbound rate, which is most suitable for high-demand scenarios. TL strategy was used to increase the customers' service level and reduce the unit cost.

The average total unit cost is calculated for the $95 \%$ and the $99 \%$ confidence intervals. All values are in different ranges. From the results, it is obvious that a full-truck load is the best way to decrease the unit cost. Trucking cost and holding cost are most critical in the cost model. The TL and LTL show significant differences in transportation cost. Truck-load system is the alternative for both small demand and large demand systems. The range of cost and controlling the flow rate between locations are issues to be investigated and explained about the behavior of the system.

\section{REFERENCES}

Anily, S., and A. Federgruen. 1993. Two-echelon distribution system with vehicle routing cost and central inventories. Operations Research 41, 37-47.

Banks, J., S.J. Carson, L.B. Nelson, and M.D. Nicol. 2005. Discrete-event System Simulation (Upper Saddle River, NJ: Pearson Prentice Hall). Qu, W.W., H.J. Bookbinder, \& P. Iyogun, 1999. An integrated inventory-transaction system with modified periodic policy for multiple products. European Journal of Operational Research 115, 254-269.

Brimberg, J., and F.R. Love. 1998. Solving a class of two-dimensional un-capacitated location - allocation problem by dynamic programming. Operations Research 46, 702-709.

Chu, C.W. 2005. A heuristic algorithm for the truckload and less-than-truckload problem. European Journal of Operational Research 165, 657-667.

Farahmand, K., and A. Balasubramanian. 2002. Solving logistics and transportation problems in a job shop. I In Proceedings of the 2002 Winter Simulation Conference ed. E. Yücesan, C. H. Chen, J. L. Snowdon, J. M. Charnes, 1052-1059. Piscataway, New Jersey: Institute of Electrical and Electronics Engineers, Inc.

Harrell, C., K.B. Ghosh, and O.R. Bowden, 2003. Simulation Using ProModel (Singapore: McGraw-Hill Education (Asia).

Jain, S., C.C. Lim, B.P. Gan, and Y.H. Low. 1999. Criticality of detailed modeling in semiconductor supply chain simulation. In: Proceedings of the 1999 Winter Simulation Conference, ed. P.A. Farrington, H.B. Nembhard, D.T. Sturrock, G.W. Evans, 888-896.Piscataway, New Jersey: Institute of Electrical and Electronics Engineers, Inc.

Jayaraman, V. 1998. Transportation, facility location, and inventory issues in distribution network design. International Journal of Operations \& Production management 18, 471-494.

Kleijnen, P.C.J. 2005. Supply chain simulation tools and techniques: a survey. International Journal of Simulation and Process Modeling 1, 82-89.

Lee, E., and K. Farahmand. 2008. Impact of demand variability on supply chain performance. In Proceedings of the 2008 Industrial Engineering Research Conference, J. Fowler and S. Mason, eds., 13381343.

Melachrinoudisa, E., A. Messac, and H. Min. 2005. "Consolidating a warehouse network: A physical programming approach,” International Journal of Production Economics 97, 1-7.

Pujawan, I.N. 2004. The effective of lot sizing rules on order variability. European Journal of Operational Research 159, 617-635.

Ruiz-Torres, A.J., and J.E. Tyworth. 1997. Simulation based approach to study the interaction of scheduling and routing on a logistic network, In Proceedings of the 1997 Winter Simulation Conference, eds. 
S.G. Henderson, B. Biller, M. Hsieh, J. Shortle, J. D. Tew, R. R. Barton, 1189-1194. Piscataway, New Jersey: Institute of Electrical and Electronics Engineers, Inc.

Sargent, G.R. 2004. Validation and verification of simulation models. In Proceedings of the 2004 Winter Simulation Conference, eds. R. G. Ingalls, M. D. Rossetti, J. S. Smith, and B. A. Peters, 17-28. Piscataway, New Jersey: Institute of Electrical and Electronics Engineers, Inc.

Sargent, G.R. 2009. Verification and validation of simulation models. In Proceedings of the 2009 Winter Simulation Conference, eds. M. D. Rossetti, R. R. Hill, B. Johansson, A. Dunkin and R. G. Ingalls, 162-176. Piscataway, New Jersey: Institute of Electrical and Electronics Engineers, Inc.

Song, L., X. Li., and A., Garcia-Diaz. 2008. Multi-echolon supply chain simulation using metamodel. In Proceedings of the 2008 Winter Simulation Conference, eds. S. J. Mason, R. R. Hill, L. Mönch, O. Rose, T. Jefferson, J. W. Fowler, 2691-2699. Piscataway, New Jersey: Institute of Electrical and Electronics Engineers, Inc.

Suwanruji, P., and S.T. Enns. 2004. Evaluating the performance of supply chain simulations with tradeoffs between multiple objectives, In Proceedings of the 2004 Winter Simulation Conference, eds. R. G. Ingalls, M. D. Rossetti, J. S. Smith, and B. A. Peters, 1399-1402. Piscataway, New Jersey: Institute of Electrical and Electronics Engineers, Inc.

Vroblefski, M., R. Ramesh, and S. Zionts. 2000. Efficient lot-sizing under a differential transportation cost structure for serially distributed warehouses. European Journal of Operational Research 127, 574-593.

\section{AUTHOR BIOGRAPHIES}

EUNSU LEE is a Ph.D. Candidate in the Transportation and Logistics Program at North Dakota State University (NDSU). He received his M.S. in Industrial Management and Engineering from NDSU in 2006, M.B.A. in Operations Management at Hanyang University in Seoul in 2000, and B.E. in Information Engineering at Kwandong Univeristy in GangNeung, South Korea in 1997. His research focuses on logistics and global supply chain management, scientific emergency management, routing analysis using simulation and Geographic Information Systems (GIS), and management information systems. He has many experiences in System Integration, Enterprise Resource Planning and logistics consulting. His email address is <eunsu. leeendsu.edu>.

KAMBIZ FARAHMAND is currently a Professor and Department Head in the Department of Industrial and Manufacturing Engineering at North Dakota State University. Dr. Farahmand has over 28 years of experience as an engineer, manager, and educator. His primary teaching and research activities are in the areas of Manufacturing Systems, Healthcare, Human Exposure and Physiology Simulation, Simulation and Modeling, Operations \& Materials Management, and Strategic Planning. He is a registered Professional Engineer in North Dakota and Texas. His email address is <kambiz. farahmandendsu.edu>. 